\title{
Predicting the influence of multiple components on microbial inhibition using a logistic response model - a novel approach
}

\author{
Cynthia J Henley-Smith ${ }^{1 \dagger}$, Francois E Steffens ${ }^{2+}$, Francien S Botha ${ }^{3+}$ and Namrita Lall ${ }^{1{ }^{*+}}$
}

\begin{abstract}
Background: There are several synergistic methods available. However, there is a vast discrepancy in the interpretation of the synergistic results. Also, these synergistic methods do not assess the influence the tested components (drugs, plant and natural extracts), have upon one another, when more than two components are combined.
\end{abstract}

Methods: A modified checkerboard method was used to evaluate the synergistic potential of Heteropyxis natalensis, Melaleuca alternifolia, Mentha piperita and the green tea extract known as TEAVIGO ${ }^{\mathrm{TM}}$. The synergistic combination was tested against the oral pathogens, Streptococcus mutans, Prevotella intermedia and Candida albicans. Inhibition data obtained from the checkerboard method, in the form of binary code, was used to compute a logistic response model with statistically significant results $(p<0.05)$. This information was used to construct a novel predictive inhibition model.

Results: Based on the predictive inhibition model for each microorganism, the oral pathogens tested were successfully inhibited (at 100\% probability) with their respective synergistic combinations. The predictive inhibition model also provided information on the influence that different components have upon one another, and on the overall probability of inhibition.

Conclusions: Using the logistic response model negates the need to 'calculate' synergism as the results are statistically significant. In successfully determining the influence multiple components have upon one another and their effect on microbial inhibition, a novel predictive model was established. This ability to screen multiple components may have far reaching effects in ethnopharmacology, agriculture and pharmaceuticals.

Keywords: Synergism, Oral pathogens, Checkerboard method, Heteropyxis natalensis, Melaleuca alternifolia, Mentha piperita, TEAVIGO ${ }^{\mathrm{TM}}$

\section{Background}

Synergistic interaction between components i.e. drugs, plant and natural extracts can enhance their efficacy and bioactivity against a target. Furthermore, synergy reduces toxicity, lowers the dosage and decreases adverse side effects, as well as combating antimicrobial resistance $[1,2]$. Several synergistic methods and the methods used to calculate synergy, have been reviewed [3]. However, there

\footnotetext{
* Correspondence: namrita.lall@up.ac.za

${ }^{\dagger}$ Equal contributors

Department of Plant Science, Faculty of Natural and Agriculture Sciences, University of Pretoria, Pretoria 0002, South Africa

Full list of author information is available at the end of the article
}

appears to be vast discrepancies in the interpretation of synergistic results.

There is also limited information available with regards to assessing the influence multiple components have upon one another in combination. Three-component combinations have been proven successful in enhancing bioactivity [4-8]. However, the more components added in combination, the more difficult it becomes to assess the influence these components have upon each other's bioactivity. The overall influence of the combination against the selected target would also be affected. This investigation aims to use 'a statistical approach that would allow for a more reliable and qualitative assessment of pharmacological 
interactions' [3]. The influences of multiple components upon one another and their effect on microbial inhibition were also investigated.

An indigenous South African plant, Heteropyxis natalensis was combined with the essential oils of Melaleuca alternifolia and Mentha piperita as well as the green tea extract known as TEAVIGO ${ }^{\mathrm{Ts}}$. Combinations of these were used against the oral pathogens, Streptococcus mutans, Prevotella intermedia and Candida albicans [9].

\section{Methods}

\section{Plant material}

Aerial plant parts, comprising of leaves and twigs of $H$. natalensis was collected. The plant parts were collected from the University of Pretoria's experimental farm during January, 2013. A voucher specimen was prepared and identified at the H.G.W.J. Schwelcherdt Herbarium (PRU), University of Pretoria. Melaleuca alternifolia essential oil (Holistic Emporium cc, Gauteng, South Africa), Mentha piperita essential oil (Holistic Emporium cc, Gauteng, South Africa), and TEAVIGO ${ }^{\mathrm{Tm}}$ (Chempure (Pty) Ltd, Silverton, South Africa), were purchased for the present investigation.

\section{Preparation of extract}

The plant material was air dried at room temperature $\left(25^{\circ} \mathrm{C}\right)$, and ground to a fine powder using a standard food processor. The powdered material was extracted with ethanol (Merck Chemicals (Pty) Ltd Wadeville, South Africa) under pressure (100 bar) and regulated temperature of $50^{\circ} \mathrm{C}$ in a BUCHI Speed Extractor, E-916 (BUCHI Labortechnik AG, Switzerland). The solvent was evaporated at low boiling point in a Genevac, EZ-2 plus (Genevac SP Scientific, UK), after which the extract was subjected to antimicrobial tests.

\section{Microbial strains}

The microorganisms used in this study included Prevotella intermedia (ATCC 25611), Streptococcus mutans (ATCC 25175) and Candida albicans (ATCC 10231). The bacteria were grown on Casein-peptone Soymeal-peptone (CASO) Agar (Merck Chemicals (Pty) Ltd Wadeville, South Africa) enriched with $1 \%$ sucrose (Merck Chemicals (Pty) Ltd Wadeville, South Africa) under anaerobic conditions in an anaerobic jar with Anaerocult ${ }^{\oplus}$ A (Merck Chemicals (Pty) Ltd Wadeville, South Africa), at $37^{\circ} \mathrm{C}$ for 48 hours. Candida albicans was grown on Sabouraud Dextrose $4 \%$ Agar (SDA) (Merck Chemicals (Pty) Ltd Wadeville, South Africa), at $37^{\circ} \mathrm{C}$ for 48 hours. Sub-culturing was done every second week. Inocula were prepared by suspending microbial test organisms in their respective broths until turbidity was compatible with McFarland Standard 1 (Merck Chemicals (Pty) Ltd Wadeville, South Africa) [10]. Therefore, the colony forming units $(\mathrm{CFU} / \mathrm{ml})$ for

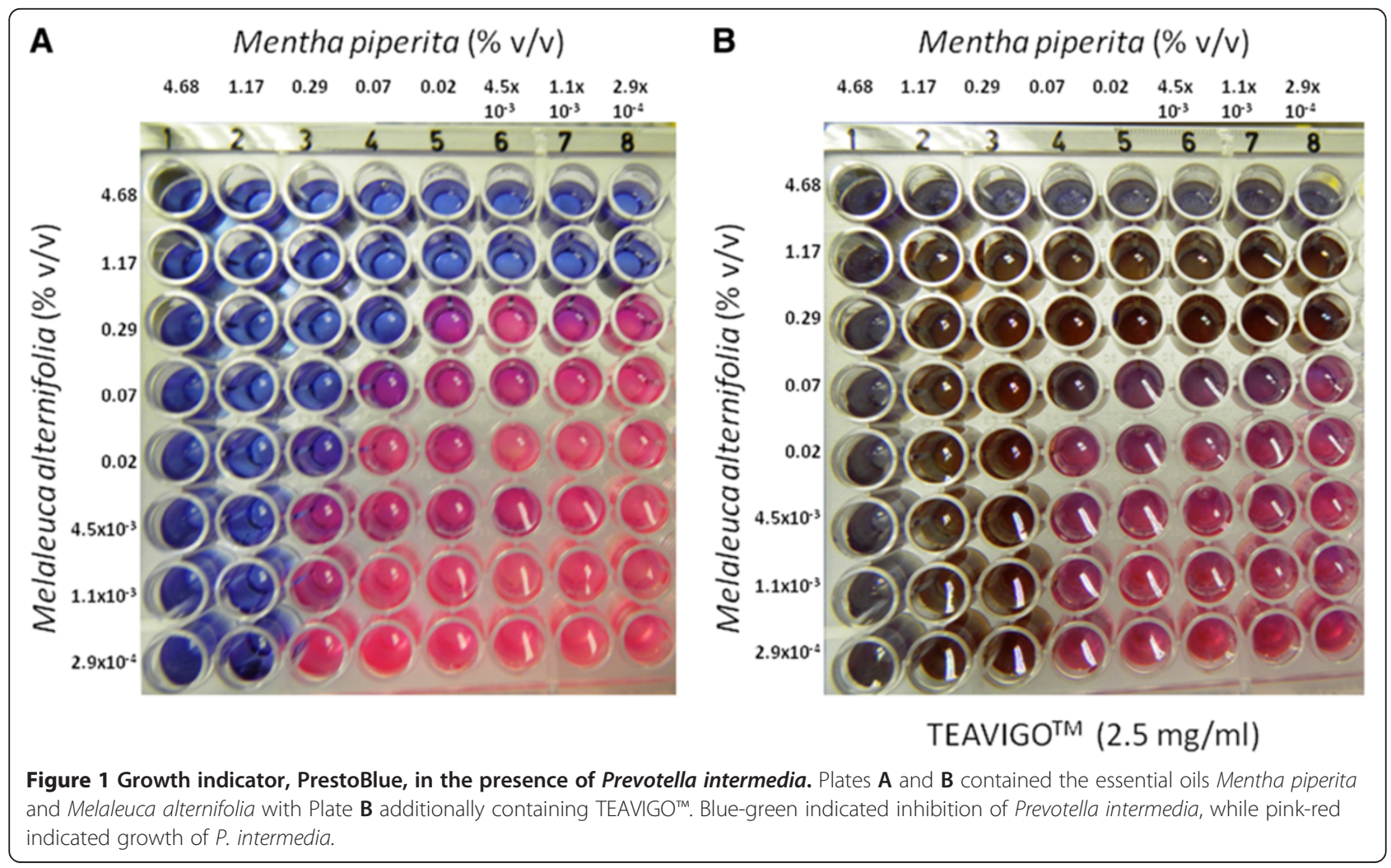


P. intermedia was $40 \times 10^{7}(\mathrm{CFU} / \mathrm{ml})$, S. mutans was $30 \times$ $10^{7}(\mathrm{CFU} / \mathrm{ml})$ and C. albicans was $4 \times 10^{7}(\mathrm{CFU} / \mathrm{ml})$ for each bioassay.

\section{Antimicrobial susceptibility testing}

To determine the effects of combinations of $H$. natalensis, M. alternifolia essential oil, M. piperita essential oil and TEAVIGO $^{\mathrm{m}}$, the minimum inhibitory concentration (MIC) of each component was determined first using the antimicrobial microtiter-plate method [11]. A stock solution of the ethanol extract of $H$. natalensis was prepared in 20\% dimethyl sulphoxide (DMSO) (Merck Chemicals (Pty) Ltd); while TEAVIGO ${ }^{\mathrm{ms}}$ was dissolved in distilled water.
The stock solutions were serially diluted in enriched CASO broth (Merck Chemicals (Pty) Ltd) for the bacteria and Sabouraud Dextrose 4\% broth (Merck Chemicals (Pty) Ltd) for Candida; in the 96-well microtiter-plate adding $100 \mu \mathrm{l}$ of a McFarland Standard 1 inoculum of 48 hour old microorganisms grown at $37^{\circ} \mathrm{C}$. The final concentration of the extract and TEAVIGO ${ }^{\text {tw }}$ ranged from $0.10-12.5 \mathrm{mg} / \mathrm{ml}$ and the positive control, $1.25 \% \mathrm{v} / \mathrm{v}$ chlorhexidine gluconate (CHX) (Dental Warehouse, Sandton, South Africa), ranged from $4.77 \times 10^{-6}-0.31 \% \mathrm{v} / \mathrm{v}$. The essential oils were dissolved in 10\% Tween (80) (Merck Chemicals (Pty) Ltd Wadeville, South Africa). The final concentration tested of the essential oils ranged from $1.6 \times 10^{-5}-1.25 \% \mathrm{v} / \mathrm{v}$. The

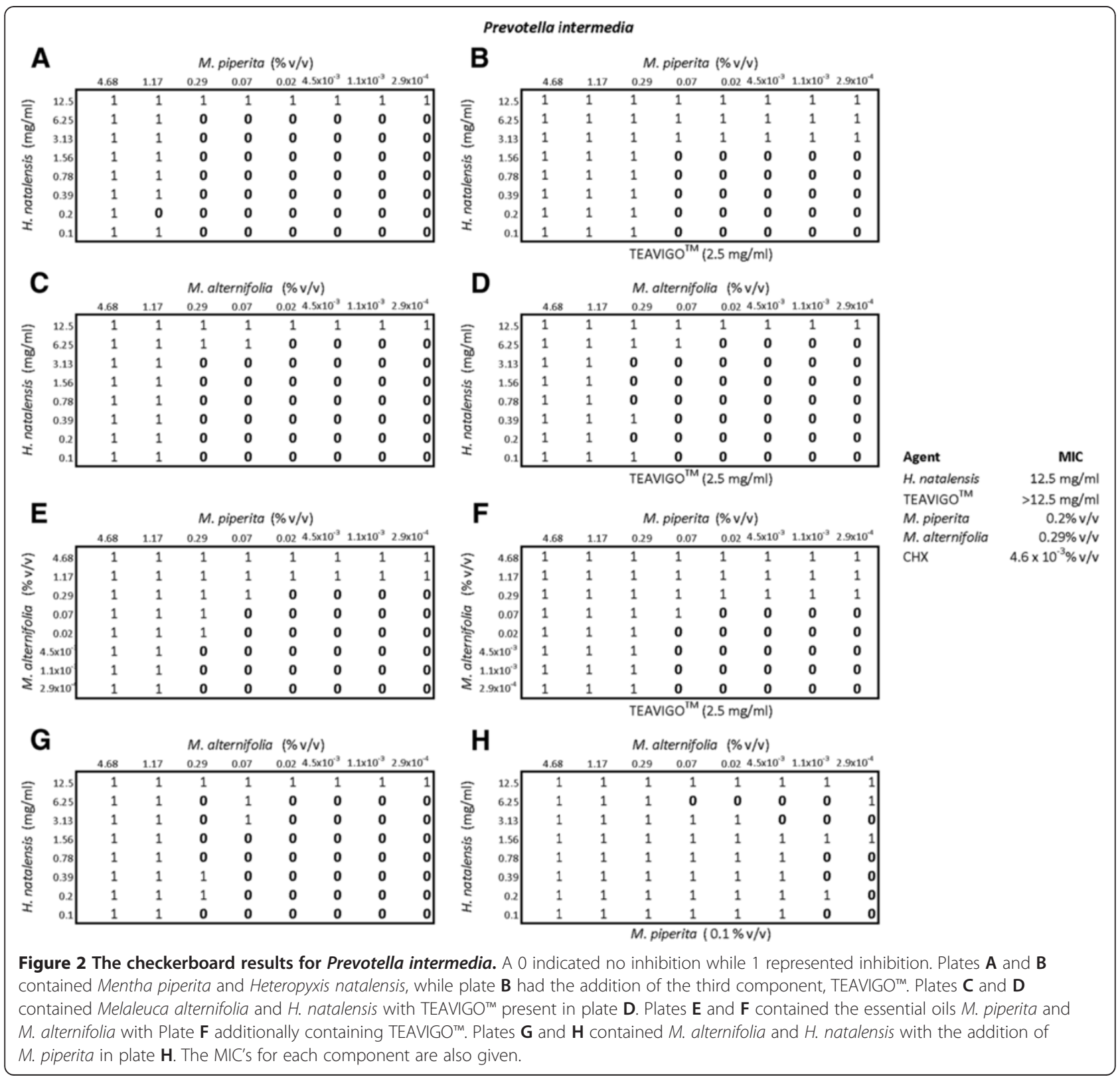


highest concentration of the solvents DMSO (5\%) and Tween 80 (2\%) were found to be non-toxic to the microorganisms tested. The inoculated plates were incubated at $37^{\circ} \mathrm{C}$, under anaerobic and aerobic conditions respectively for 24 hours before adding $20 \mu \mathrm{l}$ of the colour indicator PrestoBlue [12]. The MIC was defined as the lowest concentration that inhibited the colour change of PrestoBlue.

\section{Synergistic assay}

The synergistic activity of the samples was determined using a modified checkerboard method. The basic design is a logarithmic design with the dosages halved at each step. Full 2-factor factorial designs were used for two factors at a time with equally spaced dosages for the other factors. The individual designs were compounded in such a way that all two-way interactions and some three-way interactions could be estimated. Two 96-well plates were prepared: the first one was used to make two-fold serial dilutions of $H$. natalensis (50 $\mu \mathrm{l}$ ) in horizontal orientation, and the second plate, was used to make five-fold serial dilutions of $M$. alternifolia in the vertical orientation. Both dilutions were made in enriched CASO broth for the selected bacteria, and Sabouraud Dextrose $4 \%$ broth for the yeast, $C$. albicans. For the two-fold dilutions, $50 \mu \mathrm{l}$ of broth was pipetted per well for the first plate and $200 \mu \mathrm{l}$ for the five-fold dilutions in the second plate. Using a

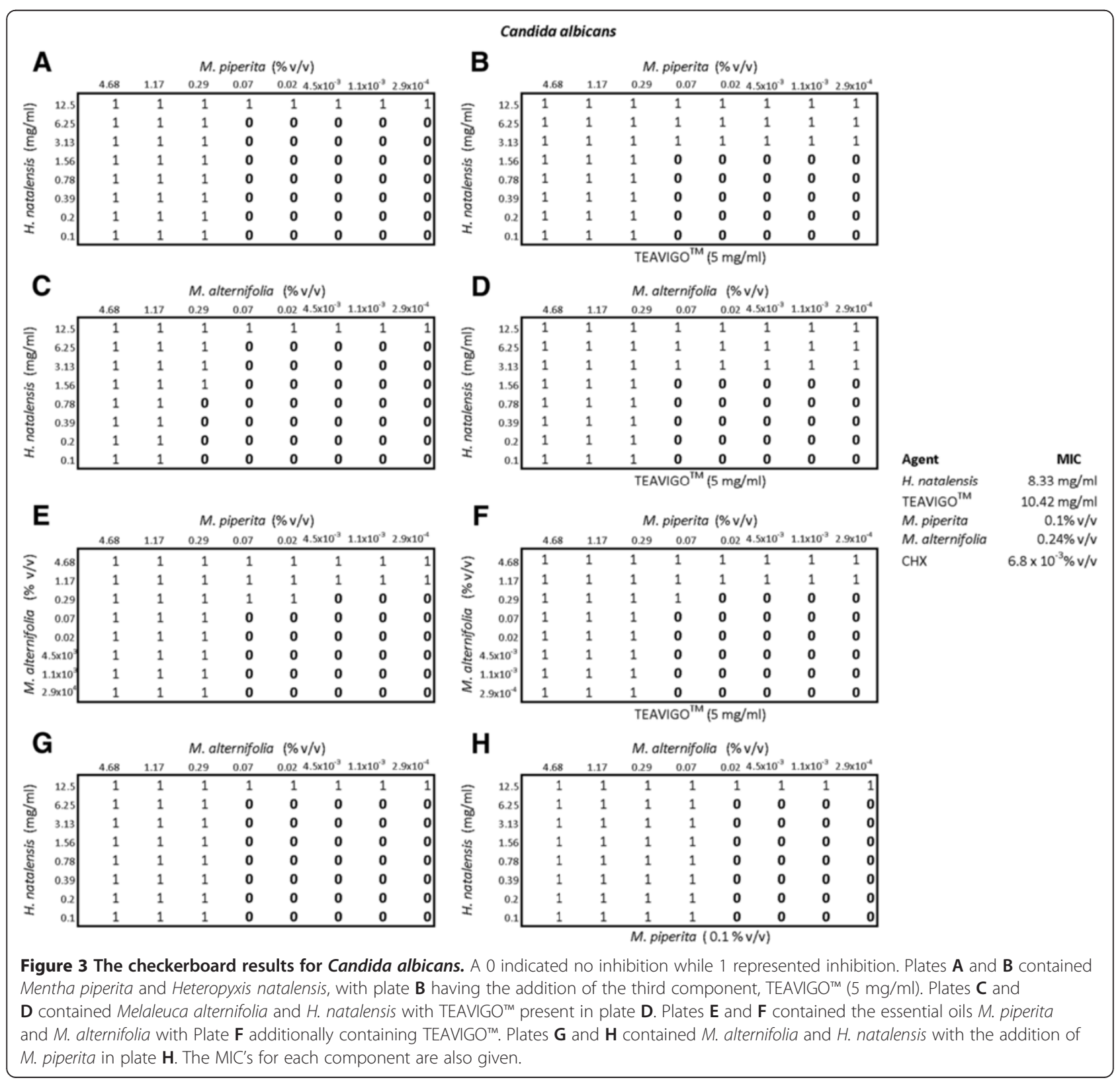


multichannel pipette, $50 \mu \mathrm{l}$ of $M$. alternifolia was transferred to the first plate, $50 \mu \mathrm{l}$ of the respective broth was added and then $50 \mu \mathrm{l}$ of bacterial suspension was added to each well and incubated for $24 \mathrm{~h}$ at $37^{\circ} \mathrm{C}$; after which $20 \mu \mathrm{l}$ of PrestoBlue was used to indicate bacterial growth $[12,13]$. The concentration range of $H$. natalensis in combination ranged from $0.097-12.5 \mathrm{mg} / \mathrm{ml}$, while the essential oils ranged from $1.6 \times 10^{-5}-1.25 \% \mathrm{v} / \mathrm{v}$.

A third plate was prepared at the same time in the exact same manner as the first plate except that instead of $50 \mu \mathrm{l}$ of additional broth; $50 \mu \mathrm{l}$ of a third component, $M$. piperita was added at a sub-MIC value at a fixed concentration to all wells. The sub-MIC concentrations of $M$. piperita and TEAVIGO ${ }^{\text {Ta }}$ were determined on the basis of MIC values previously obtained.

This process was repeated for all the combinations of the four components for each microorganism tested.

The MIC's of each component tested (as previously described) were also conducted at the same time acting as controls and a comparison. The concentration range of $H$. natalensis and TEAVIGO ${ }^{\mathrm{Tw}}$ ranged from $0.097-12.5 \mathrm{mg} /$ $\mathrm{ml}$, while the essential oils ranged from $1.6^{\mathrm{mm}} 10^{-5}-1.25 \% \mathrm{v} /$ v. CHX was again utilized as a positive control.

Once the plates were developed with PrestoBlue, each well was assigned either a 0 to indicate no inhibition or a 1 to indicate inhibition for the logistic response model.

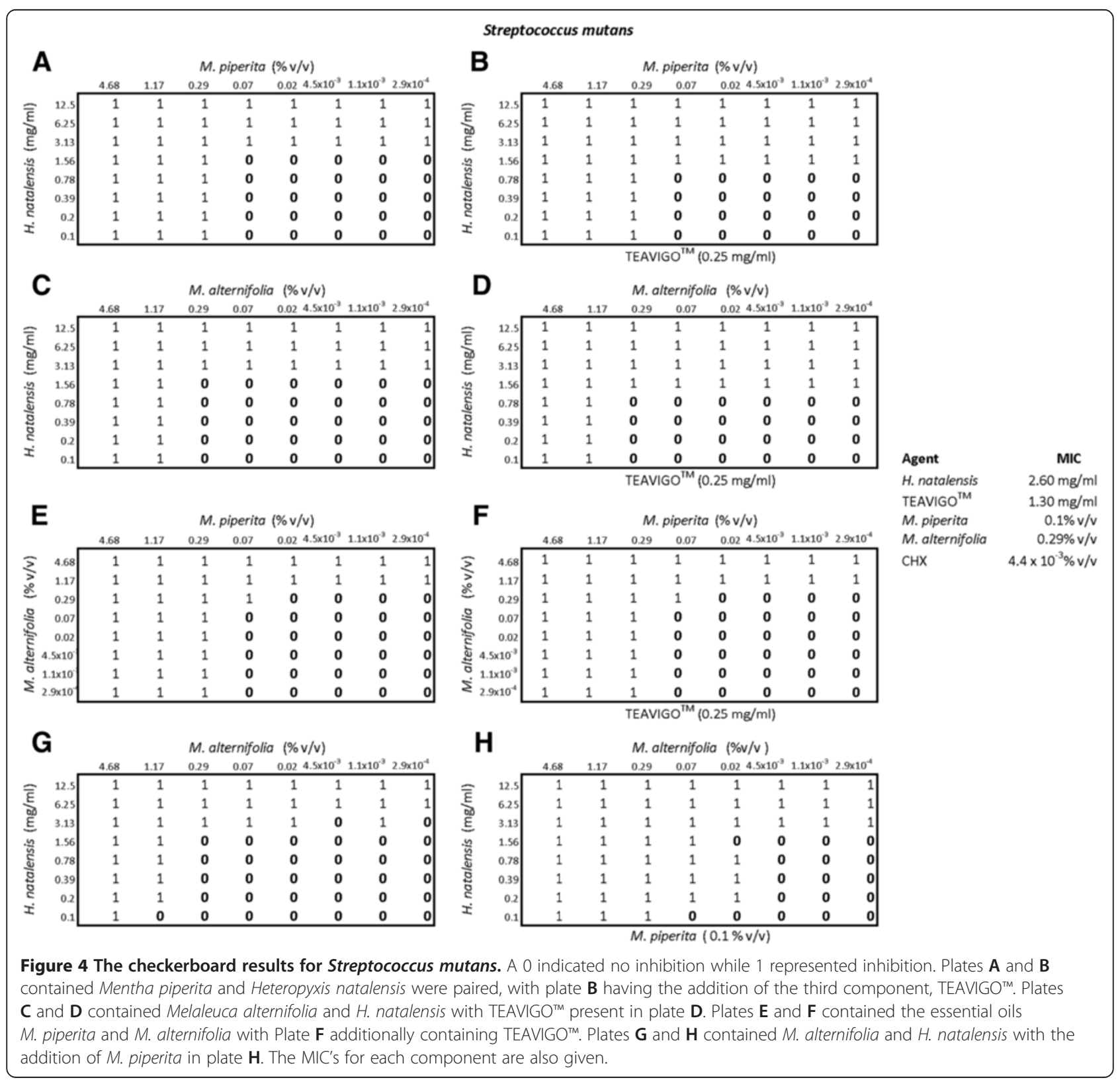


This information was used to construct a predictive inhibition model (IBM $\odot$ SPSS $\odot$ version 22) for each microorganism where the antimicrobial ability of the different combinations was tested as described in the antimicrobial susceptibility testing [11].

\section{Results}

Antimicrobial susceptibility testing

The checkerboard method was utilized as a screening tool for the reduction of MIC values. This method also provided numerous concentration variables for the components under investigation and their inhibition potential (Figure 1). The results were converted to binary code; with 0 representing no inhibition (pink-red), and 1 representing inhibition (blue). This data was then used to compute the logistic response model.

In determining the antimicrobial susceptibility of $P$. intermedia (Figure 2), the addition of TEAVIGO ${ }^{\mathrm{Tm}}$ (2.5 mg.ml) to plate $\mathrm{B}$ (of paired plates $\mathrm{A}$ and $\mathrm{B}$ ) reduced the $\mathrm{MIC}$ of H. natalensis from $12.5 \mathrm{mg} / \mathrm{ml}$ to $3.13 \mathrm{mg} / \mathrm{ml}$ and that of M. piperita from $1.17 \% \mathrm{v} / \mathrm{v}$ to $0.29 \% \mathrm{v} / \mathrm{v}$. In plates C and D the addition of TEAVIGO ${ }^{\mathrm{Tm}}$ seemed to have little effect on either $H$. natalensis or $M$. alternifolia; however, when TEAVIGO $^{\mathrm{Tm}}$ was added to the essential oils, $M$. piperita and M. alternifolia (plates E and F) both essential oils MIC's were reduced from $1.17 \% \mathrm{v} / \mathrm{v}$ to $0.29 \% \mathrm{v} / \mathrm{v}$ overall. In plates $\mathrm{G}$ and $\mathrm{H}$ with $H$. natalensis and $M$. alternifolia and the addition of $M$. piperita in plate $\mathrm{H}$ there was a significant decrease in both components MIC's. Even though the pattern of inhibition to no-inhibition was a little scattered, the overall reduction of the MIC of $H$. natalensis from $12.5 \mathrm{mg} / \mathrm{ml}$ to $1.56 \mathrm{mg} / \mathrm{ml}$ and for $M$. alternifolia from $1.17 \% \mathrm{v} / \mathrm{v}$ to $4.5 \times 10^{-3} \% \mathrm{v} / \mathrm{v}$ was obtained. There is a significant increase in the antimicrobial activity of the components in combination when compared to the MIC values of the individual components.

With $C$. albicans (Figure 3), the addition of TEAVIGO at a sub-MIC $(5 \mathrm{mg} / \mathrm{ml})$ in plate $\mathrm{B}$, reduced the MIC of H. natalensis from $12.5 \mathrm{mg} / \mathrm{ml}$ to $3.13 \mathrm{mg} / \mathrm{ml}$ but had no impact on the MIC of M. piperita. The MIC of $H$. natalensis was again reduced in plate $\mathrm{D}$ and the essential oil M. alternifolia was also reduced from $1.17 \% \mathrm{v} / \mathrm{v}$ to $0.29 \% \mathrm{v} / \mathrm{v}$. There was virtually no difference in plates $\mathrm{E}$ and $\mathrm{F}$ containing $M$. alternifolia and $M$. piperita with the addition of TEAVIGO ${ }^{\mathrm{Tm}}$. The addition of $M$. piperita in plate $\mathrm{H}$ reduced the MIC of $M$. alternifolia from $0.29 \% \mathrm{v} / \mathrm{v}$ to $0.07 \% \mathrm{v} / \mathrm{v}$ but had no effect on the MIC of $H$. natalensis.

Table 1 Logistic model summary for Prevotella intermedia

\begin{tabular}{cc}
\hline $\mathbf{- 2}$ Log likelihood & Nagelkerke R square $^{\mathbf{a}}$ \\
\hline 215.765 & .864
\end{tabular}

${ }^{\mathrm{a}}$ The Nagelkerke R Square is the logistic regression equivalent of the usual coefficient of determination used in multiple linear regression [16].
Table 2 Classification table for Prevotella intermedia

\begin{tabular}{llccc}
\hline \multirow{2}{*}{ Observed } & \multicolumn{3}{c}{ Predicted } \\
\cline { 3 - 5 } & & \multicolumn{2}{c}{$\mathbf{Y}$} & $\begin{array}{c}\text { Percentage } \\
\text { correct }\end{array}$ \\
\cline { 2 - 5 } & 0 & 267 & 17 & 94.0 \\
\hline Y & 1 & 20 & 336 & 94.4 \\
Overall Percentage & & & 94.2 \\
\hline
\end{tabular}

Heteropyxis natalensis on its own inhibited C. albicans at $8.33 \mathrm{mg} / \mathrm{ml}$; in combination with $M$. piperita and TEAVIGO $^{\mathrm{TM}}$ this concentration was reduced to $3.13 \mathrm{mg} /$ $\mathrm{ml}$. Melaleuca alternifolia in combination with $H$. natalensis and $M$. piperita reduced the MIC from $0.24 \% \mathrm{v} / \mathrm{v}$ (of $M$. alternifolia on its own) to $0.07 \% \mathrm{v} / \mathrm{v}$.

In determining the inhibitory effect of three components on $S$. mutans (Figure 4), there was a reduction in the MIC of $H$. natalensis from $3.13 \mathrm{mg} / \mathrm{ml}$ to $1.56 \mathrm{mg} /$ $\mathrm{ml}$ with the addition of TEAVIGO ${ }^{\mathrm{sm}}$ but there was no effect on $M$. piperita (plates A and B). The same effect was exhibited with $H$. natalensis, $M$. alternifolia and the addition of TEAVIGO ${ }^{\mathrm{m}}$ in plates $\mathrm{C}$ and $\mathrm{D}$. There was no apparent effect of TEAVIGO ${ }^{\text {Ts }}$ on the essential oils, $M$. piperita and $M$. alternifolia (plates E and F). There was a marked increase in the inhibition by $M$. alternifolia with the addition of $M$. piperita; from $1.17 \% \mathrm{v} / \mathrm{v}$ to $0.02 \% \mathrm{v} / \mathrm{v}$ (plates G and H). Melaleuca alternifolia on its own inhibited S. mutans at $0.29 \%$. In combination with $H$. natalensis and $M$. piperita this inhibitory concentration was reduced to $0.02 \% \mathrm{v} / \mathrm{v}$.

\section{Logistic response model}

The logistic response model [14] was used to predict the probability associated with each value of the binary response (Tables 1, 2, 3, 4, 5, 6, 7, 8 and 9). A stepwise procedure [15] was used to select the most important predictors. In this investigation the probability of inhibition was modeled.

Table 3 Variables in the equation for Prevotella intermedia

\begin{tabular}{lccc}
\hline & $\mathbf{B}^{\mathbf{a}}$ & S.E. $^{\mathbf{b}}$ & Sig. $^{\mathbf{c}}$ \\
\hline X1 & .662 & .072 & .000 \\
X2 & 82.473 & 11.501 & .000 \\
X3 & 60.709 & 7.536 & .000 \\
X4 & 1.068 & .220 & .000 \\
X1 by X3 & -4.795 & .690 & .000 \\
X3 by X4 & 35.518 & 18.520 & .055 \\
Constant & -6.100 & .638 & .000 \\
\hline
\end{tabular}

${ }^{\mathrm{a}}$ Regression Co-efficient.

${ }^{\mathrm{b}}$ Standard Error.

'Significance. 
Table 4 Logistic model summary for Candida albicans

\begin{tabular}{cc}
\hline $\mathbf{- 2}$ Log likelihood & Nagelkerke R square \\
\hline 92.432 & .947 \\
\hline
\end{tabular}

The response variable is $\mathrm{Y}$ as follows:

$\mathrm{Y}=0$ means no response

$\mathrm{Y}=1$ means inhibition

$X=\left(\mathrm{X}_{1}, \mathrm{X}_{2}, \mathrm{X}_{3}, \mathrm{X}_{4}\right)$ is the combination of dosages with

$\mathrm{X}_{1}$ representing $H$. natalensis, $\mathrm{X}_{2}-M$. alternifolia, $\mathrm{X}_{3}$ M. piperita and $\mathrm{X}_{4}-$ TEAVIGO $^{\mathrm{m}}$

$\mathrm{p}(X)=$ the probability of inhibition given the dosage combination

$\mathrm{O}(X)$ is the odds of obtaining inhibition

$$
O(X)=\frac{p(X)}{1-p(X)}
$$

The $\log ($ odds) is $\mathrm{LN}\{\mathrm{O}(X)\}$

The logistic regression model is a linear model (linear in terms of the regression coefficients) that links the log (odds) to the dosages and to interaction terms between the dosages.

The function is estimated by means of maximum likelihood. In this case (Table 3), the estimate is

$$
\begin{aligned}
\mathrm{LN}\{\mathrm{O}(\mathrm{X})\}= & -6.1+0.662 \mathrm{X}_{1}+82.473 \mathrm{X}_{2} \\
& +60.709 \mathrm{X}_{3}+1.068 \mathrm{X}_{4}-4.795 \mathrm{X}_{1} \mathrm{X}_{3} \\
& +35.518 \mathrm{X}_{3} \mathrm{X}_{4}
\end{aligned}
$$

The estimated odds of inhibition is then

$$
O(X)=\operatorname{EXP}(L N(O(X)))=e^{L N(O(X))}
$$

The estimated probability of inhibition is then

$$
p(X)=\frac{O(X)}{1+O(X)}
$$

\section{Validation of the models}

With the variables in the equation for Prevotella intermedia (Table 3), $80 \%$ of the original sample was randomly selected to be the training sample, and the remaining $20 \%$ formed the test sample. The model was fitted using the training sample and used to predict the outcomes of the training and validation samples. The

Table 5 Classification table for Candida albicans

\begin{tabular}{lcccc}
\hline \multirow{2}{*}{ Observed } & \multicolumn{3}{c}{ Predicted } \\
\cline { 3 - 4 } & & \multicolumn{2}{c}{$\mathbf{Y}$} & $\begin{array}{c}\text { Percentage } \\
\text { correct }\end{array}$ \\
\cline { 3 - 5 } & & $\mathbf{0}$ & $\mathbf{1}$ & 96.8 \\
\hline & 1 & 13 & 350 & 96.4 \\
\multirow{2}{*}{ Overall percentage } & & & 96.6 \\
\hline
\end{tabular}

Table 6 Variables in the equation for Candida albicans

\begin{tabular}{lccc}
\hline & $\mathbf{B}^{\mathbf{a}}$ & S.E. $^{\mathbf{b}}$ & Sig. $^{\mathbf{c}^{\mathbf{c}}}$ \\
\hline X1 & 3.488 & .852 & .000 \\
X2 & 770.772 & 207.145 & .000 \\
X3 & 773.135 & 212.726 & .000 \\
X4 & 5.946 & 1.620 & .000 \\
X1 by X3 & -61.807 & 17.021 & .000 \\
X2 by X4 & -116.903 & 32.381 & .000 \\
X3 by X4 & -4.824 & 2.252 & .032 \\
Constant & -39.892 & 10.602 & .000 \\
\hline
\end{tabular}

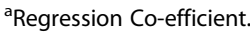

${ }^{\mathrm{b}}$ Standard Error.

'Significance.

outcome was that $92.4 \%$ of the training sample was correctly classified and $95.4 \%$ of the validation sample was correctly classified. This is considered satisfactory.

With the variables in the equation for Candida albicans (Table 6), $80 \%$ of the original sample was randomly selected to be the training sample, and the remaining $20 \%$ formed the test sample. The model was fitted using the training sample and used to predict the outcomes of the training and validation samples. The outcome was that $96.8 \%$ of the training sample was correctly classified and $95.7 \%$ of the validation sample was correctly classified. This is considered satisfactory.

With the variables in the equation for Streptococcus mutans (Table 9), $80 \%$ of the original sample was randomly selected to be the training sample, and the remaining $20 \%$ formed the test sample. The model was fitted using the training sample and used to predict the outcomes of the training and validation samples. The outcome was that $92.7 \%$ of the training sample was correctly classified and $96.7 \%$ of the validation sample was correctly classified. This is considered satisfactory.

\section{Predictive inhibition model}

A maximum of three components were tested on a microtitre plate using the modified checkerboard method. All possible combinations of the four components were tested this way (Figure 2). The $\log$ odds estimate, $\operatorname{LN}\{\mathrm{O}(X)\}$, obtained from the logistic regression model, combines the data of the four components in the predictive inhibition model. This enabled the probability of inhibition to be calculated utilizing all four components. The predictive inhibition model also provided information on the influence,

Table 7 Logistic model summary for Streptococcus mutans

\begin{tabular}{cc}
\hline $\mathbf{- 2}$ Log likelihood & Nagelkerke R square \\
\hline 162.446 & .900 \\
\hline
\end{tabular}


Table 8 Classification table for Streptococcus mutans

\begin{tabular}{|c|c|c|c|c|}
\hline \multirow[t]{3}{*}{ Observed } & & \multicolumn{3}{|c|}{ Predicted } \\
\hline & & \multicolumn{2}{|c|}{$Y$} & \multirow{2}{*}{$\begin{array}{l}\text { Percentage } \\
\text { correct }\end{array}$} \\
\hline & & 0 & 1 & \\
\hline \multirow[t]{2}{*}{ Y } & 0 & 251 & 13 & 95.1 \\
\hline & 1 & 23 & 353 & 93.9 \\
\hline Overall percentage & & & & 94.4 \\
\hline
\end{tabular}

the different components tested, had upon one another and on the probability of inhibition (Table 10).

Tables 10, 11 and 12, show further validation of the predictive models for each microorganism tested. The models were used to predict the probability of inhibition outside the experimental area, and additional experiments were performed in the laboratory to judge the performance of the models. The performance was satisfactory.

Based on the predictive inhibition model where 1 indicates the probability for $100 \%$ inhibition; P. intermedia (Table 11), C. albicans (Table 12) and S. mutans (Table 13) were successfully inhibited. At probabilities lower than $100 \%$ almost no inhibition was obtained for $P$. intermedia and $C$. albicans, while there was inhibition of $S$. mutans at 99\%. Prevotella intermedia seemed to be sensitive to the concentration of $M$. alternifolia, as no inhibition was obtained when $M$. alternifolia was decreased to $0.01 \% \mathrm{v} / \mathrm{v}$ (at a $99.8 \%$ probability).

There is a reduction in the MIC values of the individual components, when used in combination for each of the microorganisms tested (Table 14). And therefore, we can state that there is an overall increase in the inhibitory activity when the components are used in combination.

\section{Discussion}

The synergistic combination of the components had different effects on each of the microorganisms tested. This may indicate the possible mechanism of action of these components. The combinations of $M$. piperita, $H$. natalensis and TEAVIGO $^{\mathrm{Tw}}$, against $P$. intermedia, $C$. albicans and $S$.

Table 9 Variables in the equation for Streptococcus mutans

\begin{tabular}{lccc}
\hline & $\mathbf{B}^{\mathbf{a}}$ & S.E. $^{\mathbf{b}}$ & Sig. $^{\mathbf{c}^{\mathbf{c}}}$ \\
\hline X1 & 2.249 & .253 & .000 \\
X2 & 34.504 & 5.160 & .000 \\
X3 & 55.328 & 7.499 & .000 \\
X4 & 12.302 & 2.154 & .000 \\
X1 by X3 & -5.628 & .791 & .000 \\
Constant & -6.086 & .666 & .000 \\
\hline
\end{tabular}

${ }^{\mathrm{a}}$ Regression Co-efficient.

${ }^{\mathrm{b}}$ Standard Error.

'Significance.
Table 10 The influence each component had on the probability of inhibition in the predictive model for Prevotella intermedia

\begin{tabular}{ccccc}
\hline $\begin{array}{c}\text { H. natalensis } \\
\text { (mg/ml) }\end{array}$ & $\begin{array}{c}\text { M. alternifolia } \\
\text { (\% v/v) }\end{array}$ & $\begin{array}{c}\text { M. piperita } \\
\text { (\% v/v) }\end{array}$ & $\begin{array}{c}\text { TEAVIGO }^{\text {TM }} \\
\text { (mg/ml) }\end{array}$ & p \\
\hline 3.125 & & & & 0.017442 \\
3.125 & 0.05 & & & 0.523084 \\
3.125 & 0.05 & 0.05 & & 0.915183 \\
3.125 & 0.05 & 0.05 & 5 & 1.000000 \\
\hline
\end{tabular}

mutans all had similar outcomes, resulting in an increased $H$. natalensis activity against these microorganisms (plates $\mathrm{A}$ and B of Figures 2, 3 and 4). The combination of M. alternifolia, $H$. natalensis and TEAVIGO ${ }^{\mathrm{ms}}$ (plates $\mathrm{C}$ and D) resulted in an increase in the activity of $H$. natalensis against $S$. mutans and both $H$. natalensis and $M$. alternifolia against $C$. albicans. However, this combination had no apparent effect on $P$. intermedia. The reverse situation occurred for the combination of M. piperita, M. alternifolia and TEAVIGO ${ }^{\mathrm{ma}}$ (plates $\mathrm{E}$ and $\mathrm{F}$ ), where an increase in antimicrobial activity was noted for $M$. piperita and $M$. alternifolia on $P$. intermedia but there were no noticeable effects on C. albicans and S. mutans. Both Gram-positive and Gram-negative bacteria's cell walls consist of peptidoglycan. Peptidoglycan is comprised of $\mathrm{N}$-acytyl-muramic acid and $N$-acetyl-glucosamine cross linked by peptide side chains and cross-bridges; however, peptidoglycan is thicker in Gram-positive bacteria. Gram-negative bacteria also possess a periplasmic space which lies between the outer membrane and the cytoplamic membrane. It is within this space that some Gram-negative bacteria produce the lactamase enzyme that can resist drugs such as penicillin [17]. The combination of M. piperita, M. alternifolia and TEAVIGO $^{\text {Tw }}$ may target the transenvelope efflux pump in $P$. intermedia which does not occur in $S$. mutans or the eukaryotic C. albicans [18]. The combination of M. piperita, $M$. alternifolia and $H$. natalensis (plates $\mathrm{G}$ and $\mathrm{H}$ ) all resulted in an increase in $M$. alternifolia antimicrobial activity but only on $P$. intermedia was the activity of $H$. natalensis also increased. Overall it would seem that TEAVIGO $^{\mathrm{mm}}$ increases the antimicrobial inhibitory activity of $H$. natalensis; while $M$. piperita has a similar effect on its essential oil counterpart $M$. alternifolia.

The predictive inhibition model provides information of the influence the different components tested have upon one another and on the probability of inhibition. This 'determination of influence' goes beyond the classification of synergism, indifference and antagonism. A probability of inhibition value was assigned to the concentration of each individual component and in various combinations of two to four. The concentrations of each component can then be adjusted to obtain a $100 \%$ probability of inhibition. The predictive inhibition model is 
Table 11 Predictive model showing the probability of inhibition ( $p$ ) for Prevotella intermedia

\begin{tabular}{cccccc}
\hline $\begin{array}{c}\boldsymbol{H} . \\
\text { natalensis } \\
(\mathbf{m g} / \mathbf{m l})\end{array}$ & $\begin{array}{c}\boldsymbol{M} \text {. } \\
\text { alternifolia } \\
(\% \mathbf{v} / \mathbf{v})\end{array}$ & $\begin{array}{c}\boldsymbol{M} \text {. } \\
\text { piperita } \\
(\% \mathbf{v} / \mathbf{v})\end{array}$ & $\begin{array}{c}\text { TEAVIGO }^{\text {TM }} \\
(\mathbf{m g} / \mathbf{m l})\end{array}$ & $\mathbf{p}$ & Outcome \\
\hline 0.78125 & 0.002 & 0.002 & 1.25 & 0.02023 & $\begin{array}{c}\text { No } \\
\text { inhibition }\end{array}$ \\
1.5625 & 0.002 & 0.01 & 1.25 & 0.06981 & $\begin{array}{c}\text { No } \\
\text { inhibition }\end{array}$ \\
1.5625 & 0.01 & 0.01 & 1 & 0.09233 & $\begin{array}{c}\text { No } \\
\text { inhibition }\end{array}$ \\
1.5625 & 0.01 & 0.01 & 2.5 & 0.46238 & $\begin{array}{c}\text { No } \\
\text { inhibition }\end{array}$ \\
3.125 & 0.01 & 0.05 & 2.5 & 0.99795 & $\begin{array}{c}\text { No } \\
\text { inhibition }\end{array}$ \\
3.125 & 0.05 & 0.05 & 2 & 0.99969 & Inhibition \\
3.125 & 0.05 & 0.05 & 5 & 1.00000 & Inhibition \\
6.25 & 0.05 & 0.25 & 5 & 1.00000 & Inhibition \\
6.25 & 0.25 & 0.25 & 4 & 1.00000 & Inhibition \\
\hline
\end{tabular}

also based on statistically significant results $(p<0.05)$ from the logistic response model. This has reduced the need to calculate the fractional inhibitory concentration (FIC) or equivalent values.

There is a reduction in the MIC values of each individual component, when used in combination for each of the microorganisms tested (Table 14). Therefore, we can state that there is an overall increase in the inhibitory activity when the components are used in combination.

\section{Conclusions}

The use of the checkerboard method as a screening tool, utilizing the binary code to indicate inhibition

Table 12 Predictive model showing the probability of inhibition (p) for Candida albicans

\begin{tabular}{cccccc}
\hline $\begin{array}{c}\boldsymbol{H} . \\
\begin{array}{c}\text { natalensis } \\
(\mathbf{m g} / \mathbf{m l})\end{array}\end{array}$ & $\begin{array}{c}\text { M. } \\
\text { alternifolia } \\
(\% \mathbf{v} / \mathbf{v})\end{array}$ & $\begin{array}{c}\text { M. } \\
\text { piperita } \\
(\% \text { v/v) }\end{array}$ & $\begin{array}{c}\text { TEAVIGO } \\
(\mathbf{m g} / \mathbf{m l})\end{array}$ & $\mathbf{p}$ & Outcome \\
\hline 0.78125 & 0.002 & 0.002 & 2.5 & 0.00000 & $\begin{array}{c}\text { No } \\
\text { inhibition }\end{array}$ \\
1.5625 & 0.002 & 0.01 & 2 & 0.00000 & $\begin{array}{c}\text { No } \\
\text { inhibition }\end{array}$ \\
1.5625 & 0.01 & 0.01 & 2 & 0.00003 & $\begin{array}{c}\text { No } \\
\text { inhibition }\end{array}$ \\
1.5625 & 0.01 & 0.01 & 5 & 0.97528 & $\begin{array}{c}\text { No } \\
\text { inhibition }\end{array}$ \\
3.125 & 0.01 & 0.05 & 4 & 1.00000 & Inhibition \\
3.125 & 0.05 & 0.05 & 4 & 1.00000 & Inhibition \\
3.125 & 0.05 & 0.05 & 10 & 1.00000 & Inhibition \\
6.25 & 0.05 & 0.25 & 8 & 1.00000 & Inhibition \\
6.25 & 0.25 & 0.25 & 8 & 1.00000 & Inhibition \\
\hline
\end{tabular}

Table 13 Predictive model showing the probability of inhibition ( $p$ ) for Streptococcus mutans

\begin{tabular}{cccccc}
\hline $\begin{array}{c}\boldsymbol{H} . \\
\text { natalensis } \\
(\mathbf{m g} / \mathbf{m l})\end{array}$ & $\begin{array}{c}\boldsymbol{M} \text { alternifolia } \\
(\% \mathbf{v} / \mathbf{v})\end{array}$ & $\begin{array}{c}\boldsymbol{M} . \\
\text { piperita } \\
(\% \mathbf{v} / \mathbf{v})\end{array}$ & $\begin{array}{c}\text { TEAVIGO }^{\text {TM }} \\
(\mathbf{m g} / \mathbf{m l})\end{array}$ & $\mathbf{p}$ & Outcome \\
\hline 0.390625 & 0.00008 & 0.0004 & 0.390625 & 0.40661 & $\begin{array}{c}\text { No } \\
\text { inhibition }\end{array}$ \\
0.390625 & 0.0004 & 0.0004 & 0.390625 & 0.40928 & $\begin{array}{c}\text { No } \\
\text { inhibition }\end{array}$ \\
0.390625 & 0.002 & 0.002 & 0.390625 & 0.44355 & $\begin{array}{c}\text { No } \\
\text { inhibition }\end{array}$ \\
0.78125 & 0.0004 & 0.002 & 0.78125 & 0.99549 & Inhibition \\
0.78125 & 0.002 & 0.002 & 0.78125 & 0.99573 & Inhibition \\
0.78125 & 0.01 & 0.01 & 0.78125 & 0.99784 & Inhibition \\
1.5625 & 0.002 & 0.01 & 1.5625 & 1.00000 & Inhibition \\
1.5625 & 0.01 & 0.01 & 1.5625 & 1.00000 & Inhibition \\
1.5625 & 0.05 & 0.05 & 1.5625 & 1.00000 & Inhibition \\
\hline
\end{tabular}

and no inhibition and the input of those results into a logistic response model, lead to the successful construction of a predictive inhibition model. The predictive model not only gives the probability of $100 \%$ inhibition; but also shows the influence of those components upon one another and their ability to inhibit microbial growth.

The applications of this technique are almost limitless. Not only can the inhibitory effect of different plants in combinations of more than two be determined; new multiple drug combinations can be screened too. In ethnopharmacology, where the remedies of traditional healers are tested this technique will also be useful as the healers often use combinations of a variety of different plants for a treatment. In Agriculture new pesticides can also be screened as the combination of multiple components leads to the slower development of resistance.

Table 14 Comparison of the minimum inhibitory concentrations of the tested components, individually and in combination, after utilizing the predictive model

\begin{tabular}{|c|c|c|c|c|c|c|}
\hline & \multicolumn{2}{|c|}{ P. intermedia } & \multicolumn{2}{|c|}{ C. albicans } & \multicolumn{2}{|c|}{ S. mutans } \\
\hline & Alone $^{a}$ & Combo $^{b}$ & Alone $^{a}$ & Combo $^{b}$ & Alone $^{a}$ & Combo $^{b}$ \\
\hline $\begin{array}{l}\text { H. natalensis } \\
(\mathrm{mg} / \mathrm{ml})\end{array}$ & 12.50 & 3.13 & 8.33 & 3.13 & 2.60 & 0.78 \\
\hline $\begin{array}{l}\text { TEAVIGO } \\
(\mathrm{mg} / \mathrm{ml})\end{array}$ & $>12.5$ & 2.00 & 10.42 & 4.00 & 1.30 & 0.78 \\
\hline $\begin{array}{l}\text { M. piperita } \\
(\% \mathrm{v} / \mathrm{v})\end{array}$ & 0.20 & 0.05 & 0.10 & 0.05 & 0.10 & $2 \times 10^{-3}$ \\
\hline $\begin{array}{l}\text { M. alternifolia } \\
\text { (\% v/v) }\end{array}$ & 0.29 & 0.05 & 0.24 & 0.01 & 0.29 & $4 \times 10^{-4}$ \\
\hline
\end{tabular}




\section{Abbreviations}

ATCC: American type culture collection; CASO: Casein-peptone Soymeal-peptone; CFU: Colony forming units; CHX: Chlorhexidine gluconate; DMSO: Dimethyl sulphoxide; FIC: Fractional inhibitory concentration; MIC: Minimum inhibitory concentration; PRU: H.G.W.J. Schwelcherdt Herbarium; v/v: Volume per volume.

\section{Competing interests}

The University of Pretoria holds a provisional South African patent (ZA2013/ 06534) relating to the content of the manuscript. No financial benefits have been received by the authors.

\section{Authors' contributions}

CJHS conceived the study, carried out the experimentation, and drafted the manuscript. FES conducted the statistical analysis and edited the manuscript. FSB and NL supervised the project and edited the manuscript. All the authors read and approved the final manuscript.

\section{Acknowledgements}

The authors thank the University of Pretoria and the Gen Foundation for the financial research grants.

\section{Author details}

${ }^{1}$ Department of Plant Science, Faculty of Natural and Agriculture Sciences, University of Pretoria, Pretoria 0002, South Africa. ${ }^{2}$ Department of Statistics, Faculty of Natural and Agriculture Sciences, University of Pretoria, Pretoria 0002, South Africa. ${ }^{3}$ Department of Paraclinical Sciences, Phytomedicine Programme, Faculty of Veterinary Sciences, University of Pretoria, Pretoria 0002, South Africa.

Received: 4 February 2014 Accepted: 21 May 2014

Published: 13 June 2014

\section{References}

1. Cottarel G, Wierzbowski J: Combination drugs, an emerging option for antibacterial therapy. Trends Biotechnol 2007, 12:547-555.

2. Inui T, Wang Y, Deng S, Smith DC, Franzblau SG, Pauli GF: Counter-current chromatography based analysis of synergy in an anti-tuberculosis ethnobotanical. J Chromatogr 2007, 1151:211-215.

3. Van Vuuren S, Viljoen A: Plant-based antimicrobial studies - Methods and approaches to study the interaction between natural products. Planta Med 2011, 77:1168-1182.

4. Eid SY, El-Readi MZ, Wink M: Synergism of three-drug combinations of sanguinarine and other secondary metabolites with digitonin and doxorubicin in multi-drug resistant cancer cells. Phytomedicine 2012, 19:1288-1297.

5. Suliman S, van Vuuren SF, Viljoen AM: Validating the in vitro antimicrobia activity of Artemisia afra in polyherbal combinations to treat respiratory infections. S Afr J Bot 2010, 76(4):655-661.

6. Hsieh PC, Mau JL, Huang SH: Antimicrobial effect of various combinations of plant extracts. Food Microbiol 2001, 18:35-43.

7. York T, van Vuuren SF, de Wet H: An antimicrobial evaluation of plants used for the treatment or respiratory infections in rural Maputaland, KwaZulu-Natal, South Africa. J Ethnopharmacol 2012, 144:188-127.

8. Sibandze GF, van Zyl RL, van Vuuren SF: The anti-diarrhoeal properties of Breonadia salicina, Syzygium cordatum and Ozoroa sphaerocarpa when used in combination in Swazi traditional medicine. J Ethnopharmacol 2010, 132:506-511.

9. Henley Smith CJ, Steffens FE, Botha FS, Lall N: Probability of inhibition. South Afr Provisional Patent ZA. 2013/06534.

10. McFarland J: The nephelometer: An instrument for estimating the number of bacteria in suspensions for calculating the opsonic index and for vaccines. JAMA 1907, 49:1176.

11. Eloff JN: A sensitive and quick microplate method to determine the minimal inhibitory concentration of plant extract for bacteria. Plant Med 1998, 64:711-713.

12. Lall N, Henley Smith CJ, De Canha MN, Oosthuizen CB, Berrington D: Viability recomponent, PrestoBlue, in comparison with other available recomponents, utilized in cytotoxicity and antimicrobial assays. Int J Microbiol 2013. doi:10.1155/2013/420601.

13. Silva F, Ferreira S, Duarte A, Mendonça DI, Domingues FC: Antifungal activity of Coriandrum sativum essential oil, its mode of action against
Candida species and potential synergism with amphotericin B.

Phytomedicine 2011, 19:42-47.

14. Fienberg SE: The Analysis of Cross-classified Categorical Data. 2nd edition. Cambridge, Massachusetts: Massachusetts institute of Technology Press; 1980.

15. Hocking RR: The analysis and selection of variables in linear regression. Biometrics 1976, 32:1-49.

16. Nagelkerke NJD: A note on a general definition of the coefficient of determination. Biometrika 1991, 78:691-692.

17. Samaranayake LP: Essential microbiology for dentistry; with a contribution by B.M. Jones; foreword by Crispian Scully. Edinburgh, New York: Churchill Livingstone; 2002.

18. Lomovskaya O, Zgurskaya HI: Efflux Pumps from Gram-negative Bacteria: From Structure and Function to Inhibition. In Emerging Trends in Antibacterial Discovery. Part II -4 Novel Targets and Sources. Edited by Miller AA, Millar PF. Norfolk, UK: Caister Academic Press; 2011:77-105.

doi:10.1186/1472-6882-14-190

Cite this article as: Henley-Smith et al:: Predicting the influence of multiple components on microbial inhibition using a logistic response model - a novel approach. BMC Complementary and Alternative Medicine 2014 14:190.

\section{Submit your next manuscript to BioMed Central and take full advantage of:}

- Convenient online submission

- Thorough peer review

- No space constraints or color figure charges

- Immediate publication on acceptance

- Inclusion in PubMed, CAS, Scopus and Google Scholar

- Research which is freely available for redistribution 